\title{
GERMINAÇÃO DE SEMENTES DE Amburana acreana (Ducke) A. C. Sm. SUBMETIDAS A DIFERENTES CONDIÇÕES DE TEMPERATURA E DE ESTRESSE HÍDRICO ${ }^{1}$
}

\author{
ELEONORA P. DE B. C. E SILVA BELLO², MARIA CRISTINA DE F. E ALBUQUERQUE², \\ SEBASTIÃO C. GUIMARÃES ${ }^{3}$, ELISABETH A. FURTADO DE MENDONÇA ${ }^{3}$
}

\begin{abstract}
RESUMO - Este trabalho teve por objetivos avaliar o efeito da temperatura e do estresse hídrico na germinação das sementes e na formação de plântulas normais de Amburana acreana. Foram realizados dois ensaios. No primeiro, as sementes foram colocadas para germinar nas temperaturas de 20, 25 , 30,35 e $40^{\circ} \mathrm{C}$. No segundo, as sementes foram dispostas em substrato umedecido com soluções de polietilenoglicol 6000 nos seguintes potenciais hídricos: zero (testemunha), -0,2, -0,4, -0,8, -1,0 e $\quad-1,2 \mathrm{MPa}$, a $30^{\circ} \mathrm{C}$. A germinação das sementes e a formação de plântulas normais foi avaliada durante 30 dias, em cinco repetições de 20 sementes, sendo consideradas germinadas aquelas que apresentaram emissão de raiz primária com no mínimo $5 \mathrm{~mm}$ de comprimento e curvatura geotrópica positiva. Os melhores resultados, no primeiro ensaio, foram encontrados nas temperaturas de 30 e $35^{\circ} \mathrm{C}$, com maiores valores de porcentagens de germinação, sendo os tratamentos onde o processo germinativo ocorreu em menor tempo. A porcentagem de germinação, no segundo ensaio, diminuiu à medida que se reduziu a disponibilidade de água no substrato, a partir de $-0,4 \mathrm{MPa}$, e foi nula entre $-1,0$ e -1,2MPa. A formação de plântulas foi reduzida já no potencial -0,2MPa, sendo totalmente inibida entre $-0,4$ e $-0,8 \mathrm{MPa}$. Conclui-se que a temperatura de $30^{\circ} \mathrm{C}$ é mais recomendada para a condução do teste de germinação por propiciar melhores condições para o processo germinativo, com maior porcentagem de plântulas normais e menores porcentagens de plântulas anormais e de sementes deterioradas. A redução na disponibilidade hídrica diminui a germinação das sementes e a formação de plântulas de cerejeira e os limites para germinação ocorrem na faixa de zero a -1,0MPa e, para formação de plântulas, de zero a - $0,4 \mathrm{MPa}$.
\end{abstract}

Termos para indexação: Torresia acreana, Fabaceae, viabilidade, restrição hídrica, espécie florestal.

\section{Amburana acreana SEED GERMINATION SUBMITTED TO WATER STRESS AND OF THE TEMPERATURE}

\begin{abstract}
The aim of this study was verify the influence of the temperature and water stress in the seeds germination and seedling formation in Amburana acreana. Two assays had been carried through. In the first one, the seeds had been placed to germinate in the temperatures of 20, 25, 30, 35 and $40^{\circ} \mathrm{C}$. In the second, the seeds were placed to germinate in paper towel moistened with solutions of polietilenoglicol 6000 in the following osmotic potentials: zero, $-0.2,-0.4,-0.8,-1.0$ and $-1.2 \mathrm{MPa}$, in $30^{\circ} \mathrm{C}$. The germination of the seeds and normal seedling was evaluated during 30 days, in the five replications of 20 seeds, and was considered germinated when the seeds have primary root with at
\end{abstract}

\footnotetext{
${ }^{1}$ Submetido em 29/01/2007. Aceito para publicação em 15/05/2007. Parte da dissertação do primeiro autor apresentada a FAMEV/UFMT.
}

${ }^{2} \mathrm{Eng}^{\mathrm{a}} \mathrm{Agr}^{\mathrm{a}}$, Mestre em Agricultura Tropical, Programa de Pós-graduação em Agricultura Tropical, FAMEV-UFMT.
${ }^{3}$ Eng. Agr., Dr., Prof. Adjunto, Dept $^{\circ}$ de Fitotecnia e Fitossanidade, FAMEV-UFMT, Av. Fernando Corrêa da Costa s/nº Coxipó, Cuiabá-MT, CEP 78060-9000.mcfa@ufmt.br. 
least five millimeters of length and positive geotropic curve. The better results, in the first assay, were found between 30 and $35^{\circ} \mathrm{C}$, with higher germination and normal seedling percentage and also those were the treatments where the germination process occurred in lesser average time. In the second assay, the percentage of germinated seeds reduced with the availability of water in the substrate at $-0.4 \mathrm{MPa}$ and was zero at -1.0 and $-1.2 \mathrm{MPa}$. Seedling was reduced at $-0.2 \mathrm{MPa}$ and was completely inhibited at -0.4 and $-0.8 \mathrm{MPa}$. From this study we recommend the temperature of $30^{\circ} \mathrm{C}$ for germination test because offer better conditions to the germination process with better percentage of seedling than the other temperatures. It was concluded that the reduction of the availability of water reduces the germination and seedling process and the limits for germination occur between zero and $-1.0 \mathrm{MPa}$ and for seedling process between zero and $-0.4 \mathrm{MPa}$.

Index terms: Torresia acreana, Fabaceae, viability, water stress, forest species.

\section{INTRODUÇÃO}

A necessidade de se conhecer os principais fatores que governam a germinação de sementes de espécies florestais nativas do Brasil adquiriu maior importância nos últimos anos, principalmente em função de derrubadas indiscriminadas para abertura de novas fronteiras agrícolas, o que compromete a biodiversidade e aumenta a lista de espécies ameaçadas de extinção. O desconhecimento da ecologia dessas espécies restringe a sua utilização e ameaça sua conservação, uma vez que a velocidade da degradação ambiental tem sido muito superior aos esforços para garantir a manutenção da biodiversidade. Há risco de perda de recursos genéticos insubstituíveis, já que muitas dessas espécies têm propriedades medicinais ainda desconhecidas e também são de grande interesse econômico. Trata-se de recursos de grande potencial que necessitam ser explorados de forma sustentável e racional para que se garanta a sua continuidade e sua exploração pelas gerações futuras.

Dentre as espécies com potencial econômico encontrase a Amburana acreana (Ducke) A. C. Sm., conhecida vulgarmente como cerejeira, pertencente à família Fabaceae. Esta espécie apresenta forma arborescente de alto fuste, ocorrendo em matas altas e fechadas na Amazônia ocidental do Brasil (AM, AC, RO e MT) e da Bolívia (Carvalho, 1994), e grande valor econômico, em função da madeira ser empregada na fabricação de móveis finos, folhas decorativas, esculturas, lambris, balcões e marcenaria em geral (Lorenzi, 2002), na obtenção de lenha de boa qualidade, na indústria e como planta medicinal (Carvalho, 1994).

O cultivo de espécies nativas, seja com finalidade econômica ou conservacionista, requer conhecimentos sobre a ecofisiologia dessas espécies e sobre a germinação e a conservação das sementes, como subsídio à formulação de práticas adequadas às diferentes etapas do seu desenvolvimento.

A germinação de sementes é um processo que requer água e calor, e, dependendo da espécie, são necessários também outros fatores, tais como oxigênio e luz (Bewley e Black, 1994). A água é essencial para ativação de enzimas, quebra de ligações químicas, translocação e uso de substâncias armazenadas (Bradford, 1994; Copeland e MacDonald, 1995), enquanto a temperatura interfere na dinâmica da absorção de água e nos limites e velocidade das reações bioquímicas, além dos processos fisiológicos que governam a germinação (Popinigis, 1985; Carvalho e Nakagawa, 2000).

De forma geral, sementes de grande número de espécies tropicais e subtropicais germinam na faixa entre $20^{\circ} \mathrm{C}$ a $30^{\circ} \mathrm{C}$ (Borges e Rena, 1993). A temperatura de $30^{\circ} \mathrm{C}$ propiciou maior velocidade de germinação em sementes de Hymenaea stigonocarpa (jatobá-do-cerrado) e Stryphnodendron adstringens (barbatimão) (Dignart, 1998), e também melhor desempenho na protrusão da raiz primária e formação de plântulas em sementes de Maquira sclerophylla (pau tanino) (Miranda e Ferraz, 1999).

Albrecht et al. (1986) estudaram o efeito de temperaturas constantes e alternadas na germinação de sementes de cerejeira e concluíram que as temperaturas de 25,30 e $25-30^{\circ} \mathrm{C}$ foram adequadas para o processo, sendo $30^{\circ} \mathrm{C}$ a recomendada por apresentar maior porcentagem de germinação. Entretanto, como se trata de uma espécie florestal não domesticada espera-se variações entre sementes de um mesmo lote, devido às diferenças entre origem e época de coleta e por isso são necessários mais estudos para aumentar a abrangência dos resultados.

O conhecimento sobre como o estresse hídrico interfere na germinação tem importância especial para a ecofisiologia, 
na avaliação dos limites de tolerância e capacidade de adaptação das espécies, uma vez que os fatores ambientais são determinantes nesse processo de germinação (Sousa, 2004). Potenciais hídricos mais negativos no meio reduzem o fluxo de água para a célula, até o ponto extremo no qual a difusão de água através do simplasto cessa e o processo de germinação é diretamente afetado (Souza e Cardoso, 2000). Santos et al. (1992) relataram que o decréscimo da germinação de sementes submetidas ao estresse hídrico é atribuído à redução da atividade enzimática, a qual promove menor desenvolvimento meristemático.

As variações obtidas na germinação de sementes de uma mesma espécie em diferentes potenciais hídricos podem refletir a disponibilidade de àgua no local de origem das sementes, indicando diferenciação de espécie em ecotipos distintos (Moore e Kid, 1982). Então, a maior ou menor capacidade de germinação de sementes submetidas ao estresse hídrico deve ser considerada nas estratégias de manejo, pois está relacionada com o estabelecimento de mudas na regeneração natural de povoamentos (Borges et al., 1991).

Considerando a importância da temperatura e disponibilidade hídrica na germinação das sementes e formação de plântulas, bem como no processo de propagação das espécies florestais, procurou-se na presente pesquisa avaliar o efeito da temperatura e do estresse hídrico na germinação das sementes e na formação de plântulas normais de Amburana acreana.

\section{MATERIAL E MÉTODOS}

As sementes de cerejeira (Amburana acreana (Ducke) A. C. Sm.) foram coletadas no município de Juína - MT, durante a primeira quinzena do mês de setembro de 2003, diretamente no chão. Em seguida, foram enviadas ao Laboratório de Análise de Sementes da Faculdade de Agronomia e Medicina Veterinária, da Universidade Federal de Mato Grosso, onde o trabalho foi conduzido no período de novembro de 2003 a março de 2004. Após a retirada das impurezas, as sementes foram acondicionadas em embalagem de papelão e armazenadas em câmara refrigerada $\left(16 \pm 3^{\circ} \mathrm{C}\right.$ e $74 \pm 8 \%$ UR) até o início de cada um dos dois ensaios.

No primeiro, as sementes foram colocadas para germinar em substrato papel toalha, na forma de rolo, umedecidas com água destilada na quantidade de 2,5 vezes a massa do papel seco, em câmaras de germinação reguladas para proporcionar as temperaturas de $20,25,30,35$ e $40^{\circ} \mathrm{C}$, com variação de $0,5^{\circ} \mathrm{C}$, e em fotoperíodo de oito horas. Os rolos de papel foram mantidos dentro de sacos plásticos transparentes para manutenção da umidade. Sempre que necessário foi feito o re-umedecimento do papel com água destilada.

No segundo ensaio, as sementes foram colocadas para germinar em substrato papel toalha, na forma de rolo, umedecidos com água destilada (testemunha) ou solução de PEG 6000 em diferentes potenciais $(-0,2,-0,4,-0,8,-1,0$ e $-1,2 \mathrm{MPa}$ ), na quantidade equivalente à 2,5 vezes a massa do papel seco. As concentrações de PEG 6000, para cada potencial, foram obtidas conforme Villela et al. (1991). As repetições de cada tratamento foram colocadas dentro de sacos plásticos, e mantidas em câmara de germinação regulada a $30^{\circ} \mathrm{C}$ e fotoperíodo de oito horas. Quando necessário foi feito o re-umedecimento das amostras com a respectiva solução de PEG 6000. Ao final do teste, as sementes não germinadas em cada tratamento foram lavadas e colocadas para germinar, em substrato papel toalha, umedecido com água para observação da continuidade do processo germinativo das mesmas.

Em ambos os ensaios foi utilizado o delineamento inteiramente casualizado, com cinco repetições de 20 sementes para cada tratamento. A avaliação foi realizada diariamente, durante 30 dias, sendo consideradas germinadas aquelas sementes que apresentaram emissão de raiz primária com no mínimo $5 \mathrm{~mm}$ de comprimento e curvatura geotrópica positiva. Observou-se também a formação de plântulas normais, seguindo os critérios de Brasil (1992). Ao final do teste foram calculados as porcentagens de germinação e de plântulas normais, nos dois ensaios, e a porcentagem de plântulas anormais, porcentagem de sementes deterioradas e tempo médio de germinação (Labouriau, 1983) no primeiro ensaio.

Os dados obtidos nas variáveis porcentagens de germinação e de plântulas normais foram submetidos à análise de variância, e as médias comparadas pelo teste de ScottKnott a 5\% de probabilidade. As análises estatísticas foram realizadas com os dados originais, uma vez que os mesmos atenderam os pressupostos de normalidade (Lilliefors $5 \%$ ) e homogeneidade de variâncias (Cochran 5\%).

\section{RESULTADOS E DISCUSSÃO}

\section{Efeito da temperatura}

A germinação das sementes foi maior nos tratamentos a 30 e $35^{\circ} \mathrm{C}$ (Tabela 1) que apresentaram valores de $77 \%$ e $84 \%$, em temperaturas acima e abaixo desse intervalo ocorreram diminuições na porcentagem de germinação. Isso demonstra que o processo de germinação das sementes 
de cerejeira é sensível à variação de temperatura sendo favorecido por ambientes mais quentes, considerando os limites biológicos desse fator. Em termos numéricos, houve maior porcentagem de germinação a $35^{\circ} \mathrm{C}$ em relação a $30^{\circ} \mathrm{C}$, mas essa ordem se inverteu quando se considerou a porcentagem de plântulas formadas. Embora essas diferenças não tenham sido estatisticamente significativas, com base na análise de outras variáveis como, plântulas anormais e sementes deterioradas, sugere-se a temperatura de $30^{\circ} \mathrm{C}$ como a mais adequada para condução do teste de germinação com sementes de cerejeira.

TABELA 1. Porcentagens e tempos médios de germinação e de plântulas normais, porcentagens de plântulas anormais e de sementes deterioradas de cerejeira em diferentes temperaturas.

\begin{tabular}{ccccccc}
\hline Temperaturas $\left({ }^{\circ} \mathrm{C}\right)$ & $\mathrm{G}^{1}(\%)$ & $\mathrm{PN}(\%)$ & $\mathrm{PA}(\%)$ & $\mathrm{SD}(\%)$ & TMG (dias) & TMPN (dias) \\
\hline 20 & $51 \mathrm{C}$ & $19 \mathrm{C}$ & 32 & 5 & 19 & 26 \\
25 & $60 \mathrm{~B}$ & $38 \mathrm{~B}$ & 22 & 4 & 17 & 22 \\
30 & $77 \mathrm{~A}$ & $65 \mathrm{~A}$ & 12 & 12 & 15 & 19 \\
35 & $84 \mathrm{~A}$ & $60 \mathrm{~A}$ & 24 & 15 & 11 & - \\
40 & $44 \mathrm{C}$ & $0 \mathrm{D}$ & 0 & 54 & & \\
\hline $\mathrm{CV}(\%)$ & 13,88 & 27,81 & & & & \\
\hline
\end{tabular}

${ }^{1}$ Médias seguidas da mesma letra maiúscula, na coluna, não diferem entre si pelo teste de Scott-Knott, a 5\% de probabilidade.

Nas temperaturas de 20 e $25^{\circ} \mathrm{C}$, a porcentagem de germinação foi mais baixa, $51 \%$ e $60 \%$, respectivamente, fato que se refletiu na menor porcentagem de plântulas normais (19 e 38\%). Nessas temperaturas, a deterioração das sementes foi menor, como também a ocorrência de patógenos, provavelmente devido à menor velocidade do processo germinativo, pois aos 30 dias as sementes apresentavam-se embebidas, sem características de apodrecimento, indicando que o processo germinativo estava apenas minimizado.

Os tempos médios de germinação e de formação de plântulas normais (Tabela 1) foram influenciados pela variação de temperatura: nas temperaturas mais baixas ocorreu o atraso do processo germinativo, enquanto, a elevação da temperatura permitiu que as sementes germinassem mais rapidamente. Na temperatura de $40^{\circ} \mathrm{C}$, o tempo médio de germinação foi menor, mas ocorreu maior porcentagem de deterioração das sementes (54\%). O fato de ocorrer germinação de sementes, mas não a formação de plântulas em temperaturas mais elevadas, limita a área onde essa espécie pode estabelecer-se e regenerar a vegetação.

A germinação das sementes pode ser interpretada como um somatório de reações parciais concatenadas envolvendo enzimas diversas, e a velocidade desse processo fisiológico dependente da temperatura de incubação. Assim, existem temperaturas nas quais a velocidade de germinação é máxima, outras nas quais a velocidade é reduzida e outras nas quais a germinação não ocorre (Borghetti e Ferreira, 2004).

$\mathrm{Na}$ Figura 1 encontram-se as porcentagens acumuladas de germinação e formação de plântulas normais, durante os 30 dias de experimento, em função da temperatura, onde se observa a dinâmica dessas variáveis, destacandose a defasagem existente a $40^{\circ} \mathrm{C}$ e, em menor extensão, a $35^{\circ} \mathrm{C}$. Nas temperaturas de 20 e $25^{\circ} \mathrm{C}$ o processo foi lento e contínuo e, ao final do experimento, as sementes não haviam estabilizado a germinação. Um teste de germinação nessas condições exigiria tempo de avaliação superior a 30 dias. Conforme Carvalho e Nakagawa (2000), baixas temperaturas reduzem a velocidade de germinação e alteram a uniformidade de emergência das plântulas e, de acordo com Bewley e Black (1994), podem diminuir a capacidade da semente em absorver água, limitando a atividade de várias vias metabólicas e reduzir a velocidade do processo germinativo.

Nas temperaturas de 30 e $35^{\circ} \mathrm{C}$, a germinação iniciou mais cedo, o mesmo ocorrendo com a formação de plântulas normais, havendo indicativo de estabilização dos resultados entre 25 e 30 dias.

Os resultados encontrados refletem o comportamento característico das espécies tropicais. A espécie Amburana acreana desenvolve-se naturalmente em regiões da Amazônia ocidental do Brasil e da Bolívia, que apresentam temperaturas mais elevadas. 
$20^{\circ} \mathrm{C}$

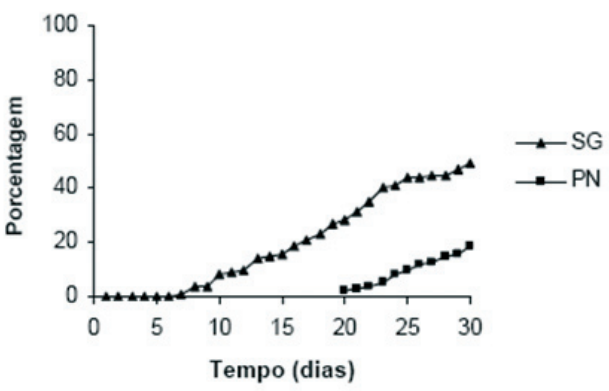

$30^{\circ} \mathrm{C}$

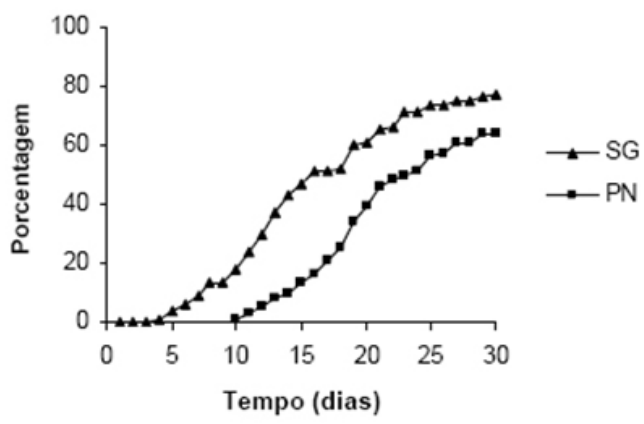

$25^{\circ} \mathrm{C}$

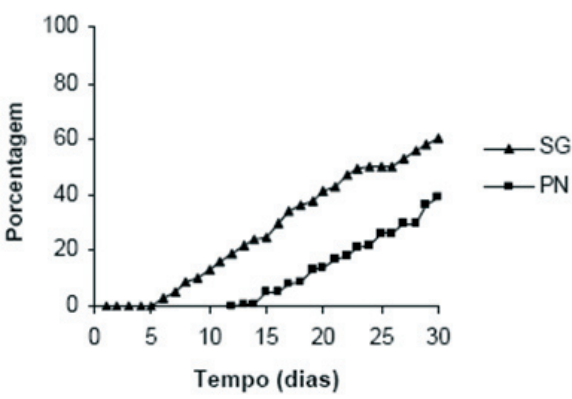

$35^{\circ} \mathrm{C}$

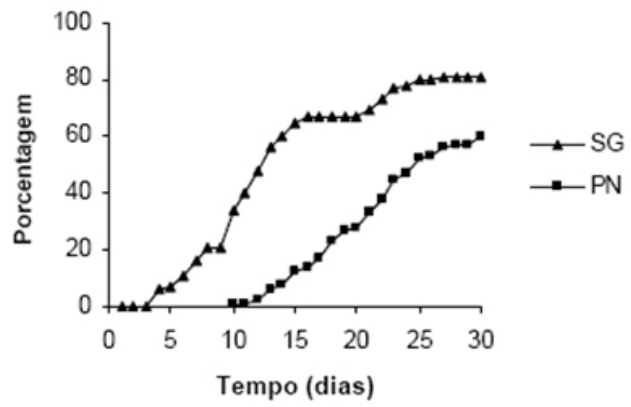

$40^{\circ} \mathrm{C}$

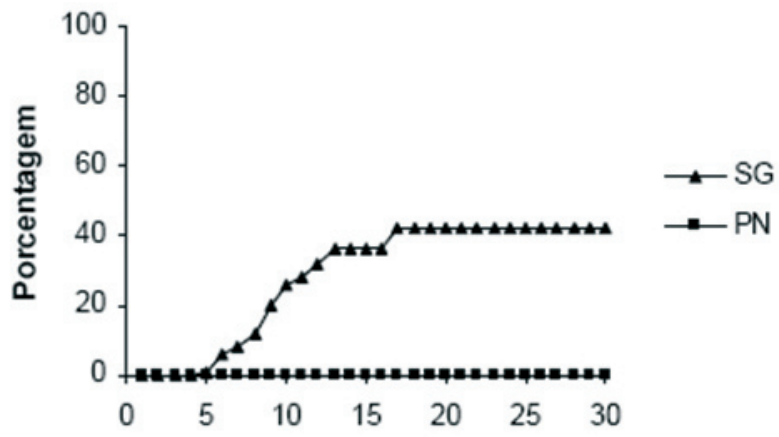

FIGURA 1. Porcentagens acumuladas de germinação (SG) e de plântulas normais (PN) de cerejeira, durante 30 dias, em diferentes temperaturas.

A maior velocidade de protrusão da raiz primária nas temperaturas mais altas ocorreu em função da embebição mais rápida e, conseqüentemente, da aceleração das reações metabólicas que ocorreram durante o processo de germinação das sementes na temperatura mais elevada. Em temperaturas supra-ótimas ocorre maior velocidade de germinação, mas somente as sementes mais vigorosas conseguem germinar, determinando assim, uma redução na porcentagem de germinação (Carvalho e Nakagawa, 2000). As temperaturas elevadas aceleram os movimentos das moléculas, tornando mais fracas as ligações químicas que associam os átomos que formam as moléculas, e as camadas de lipídios das biomembranas tornam-se mais fluidas, o que ocasiona um aumento do efluxo de material celular para o meio (Larcher, 2000).

A inibição da germinação em temperaturas abaixo do mínimo é reversível, enquanto o bloqueio da germinação por temperaturas de incubação acima do máximo é irreversível. 
As temperaturas elevadas favorecem a deterioração das sementes, como verificado com as sementes de cerejeira na temperatura de $40^{\circ} \mathrm{C}$. Houve emissão de raiz primária, mas não o desenvolvimento subseqüente, impedindo a formação de plântulas normais e favorecendo a deterioração das sementes. Ocorreu liberação de exsudados no meio germinativo e desenvolvimento de fungos na superfície das sementes.

Fato semelhante ocorreu com sementes de Chorisia speciosa St. Hil. (paineira). Quando expostas às temperaturas mais elevadas $\left(42\right.$ e $45^{\circ} \mathrm{C}$ ), liberaram maior quantidade de exsudatos no meio germinativo, com acelerado processo de deterioração (Fanti, 2001). Em sementes de B. gaudichaudii a deterioração de sementes germinadas ocorreu nas temperaturas de 40 e $45^{\circ} \mathrm{C}$ que impediram completamente a formação de plântulas normais (Añez et al., 2002).

Os resultados encontrados neste trabalho confirmaram os encontrados por Albrecht et al. (1986) com sementes da mesma espécie. Esses autores verificaram que as temperaturas de 25,30 e $25-30^{\circ} \mathrm{C}$ foram as mais adequadas para germinação de sementes de cerejeira. Entretanto, recomendaram a temperatura de $30^{\circ} \mathrm{C}$ para condução do teste de germinação devido a menor porcentagem de sementes deterioradas.

\section{Efeito do estresse hídrico}

$\mathrm{Na}$ Tabela 2 encontram-se os valores das porcentagens de germinação e de plântulas normais de cerejeira em função da disponibilidade hídrica. Verifica-se que houve efeito significativo dos diferentes potenciais hídricos sobre o processo germinativo das sementes.

TABELA 2. Porcentagens de germinação (G\%) e de plântulas normais (PN\%) de cerejeira em diferentes potenciais hídricos.

\begin{tabular}{ccc}
\hline Tratamentos $(\mathrm{MPa})$ & $\mathrm{G}^{1}(\%)$ & $\mathrm{PN}(\%)$ \\
\hline 0 & $63 \mathrm{~A}$ & $57 \mathrm{~A}$ \\
$-0,2$ & $64 \mathrm{~A}$ & $29 \mathrm{~B}$ \\
$-0,4$ & $42 \mathrm{~B}$ & $18 \mathrm{C}$ \\
$-0,8$ & $11 \mathrm{C}$ & $0 \mathrm{D}$ \\
$-1,0$ & $2 \mathrm{C}$ & $0 \mathrm{D}$ \\
$-1,2$ & $0 \mathrm{C}$ & $0 \mathrm{D}$ \\
\hline $\mathrm{CV}(\%)$ & 26,3 & 29,1 \\
\hline
\end{tabular}

Médias seguidas da mesma letra na coluna, não diferem entre si pelo teste de Scott-Knott, a 5\% de probabilidade.
Ocorreu redução na germinação e na formação de plântulas na medida em que foi reduzida a disponibilidade hídrica no substrato, sendo que as maiores porcentagens de germinação de sementes ocorreram nos tratamentos testemunha e -0,2MPa, com 63 e $64 \%$, respectivamente. Entre $-0,4$ e $-1,0 \mathrm{MPa}$ houve redução significativa na porcentagem de germinação, sendo esse processo totalmente inibido a $-1,2 \mathrm{MPa}$.

Em relação à formação de plântulas normais, o menor estresse hídrico avaliado, de $-0,2 \mathrm{MPa}$, promoveu redução de $49 \%$ nessa variável, a qual se tornou nula a $-0,8 \mathrm{MPa}$. Assim, durante o período de 30 dias, houve emissão de raiz primária a $-0,8$ e -1,0MPa, mas não houve continuidade do processo germinativo. Provavelmente, a formação de plântulas normais poderia ocorrer se o experimento fosse prolongado para mais de 30 dias.

Ao final do teste de germinação as sementes que não haviam germinado, em todos os tratamentos, foram lavadas e colocadas para germinar, em papel toalha que estava umedecido com água destilada. Verificou-se que as mesmas germinaram normalmente, indicando ter ocorrido somente a inibição da germinação nos tratamentos com a restrição hídrica.

Na Figura 2 encontram-se as porcentagens acumuladas de germinação e de plântulas normais durante o período de 30 dias sob a influência dos diferentes potenciais hídricos. Verifica-se que o início da germinação ocorreu primeiro no grupo controle e a $-0,2 \mathrm{MPa}$, no quinto dia após a semeadura. Nos potenciais - 0,4 e - $0,8 \mathrm{MPa}$, a germinação foi iniciada aos seis dias, e a -1,0MPa aos 18 dias. A germinação foi mais rápida no substrato sem restrição hídrica, até aos 21 dias, e a partir desse ponto foi igualada pelo tratamento -0,2MPa.

A velocidade de absorção de água pelas sementes decresce com a redução do potencial hídrico, aumentando o período necessário para se atingir o teor mínimo de água exigido para o início da emergência do eixo embrionário (Carvalho e Nakagawa, 2000). Em condições naturais, o estresse hídrico pode atuar de forma positiva no estabelecimento das espécies distribuindo a germinação no tempo, aumentando assim a probabilidade das plântulas encontrarem condições ambientais adequadas ao estabelecimento e desenvolvimento (Bewley e Black, 1994).

A manutenção de ampla distribuição dos valores de potencial hídrico para a germinação, em uma população de sementes, assegura que alguns indivíduos germinem mais rapidamente que outros (Fanti, 2001), aumentando as chances de estabelecimento da espécie.

O intervalo de potencial hídrico para a germinação de 
sementes de cerejeira, de $-0,2$ a $-1,0 \mathrm{MPa}$, foi mais amplo do que o encontrado para sementes de Chorisia speciosa St. Hil. (paineira), que esteve entre $-0,1$ (97\% de germinação)

\section{$0 \mathrm{MPa}$}

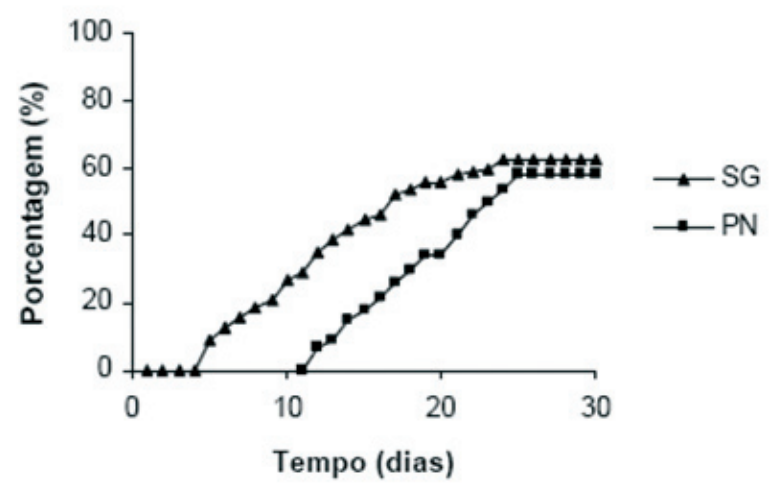

$-0,4 \mathrm{MPa}$

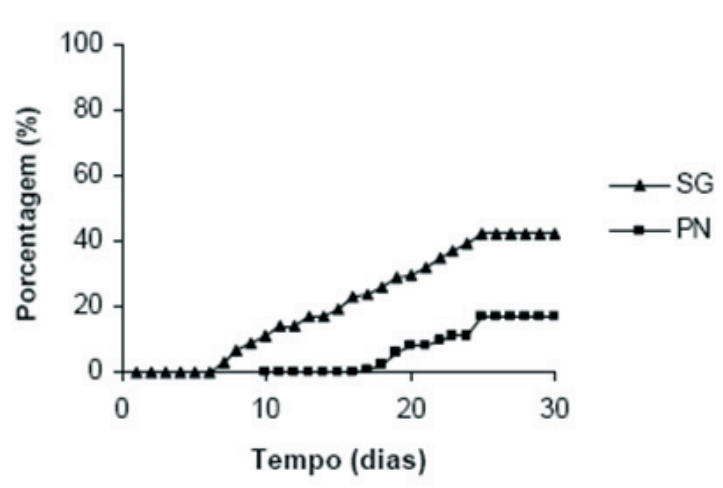

$-1,0 \mathrm{MPa}$

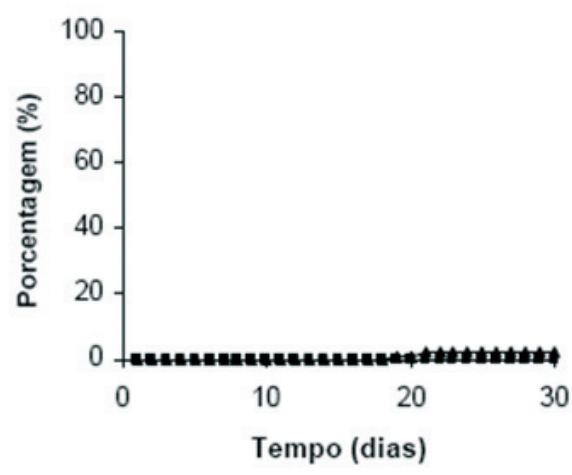

e - $0,7 \mathrm{MPa}$, sendo que nesse não ocorreu germinação (Fanti, 2001).
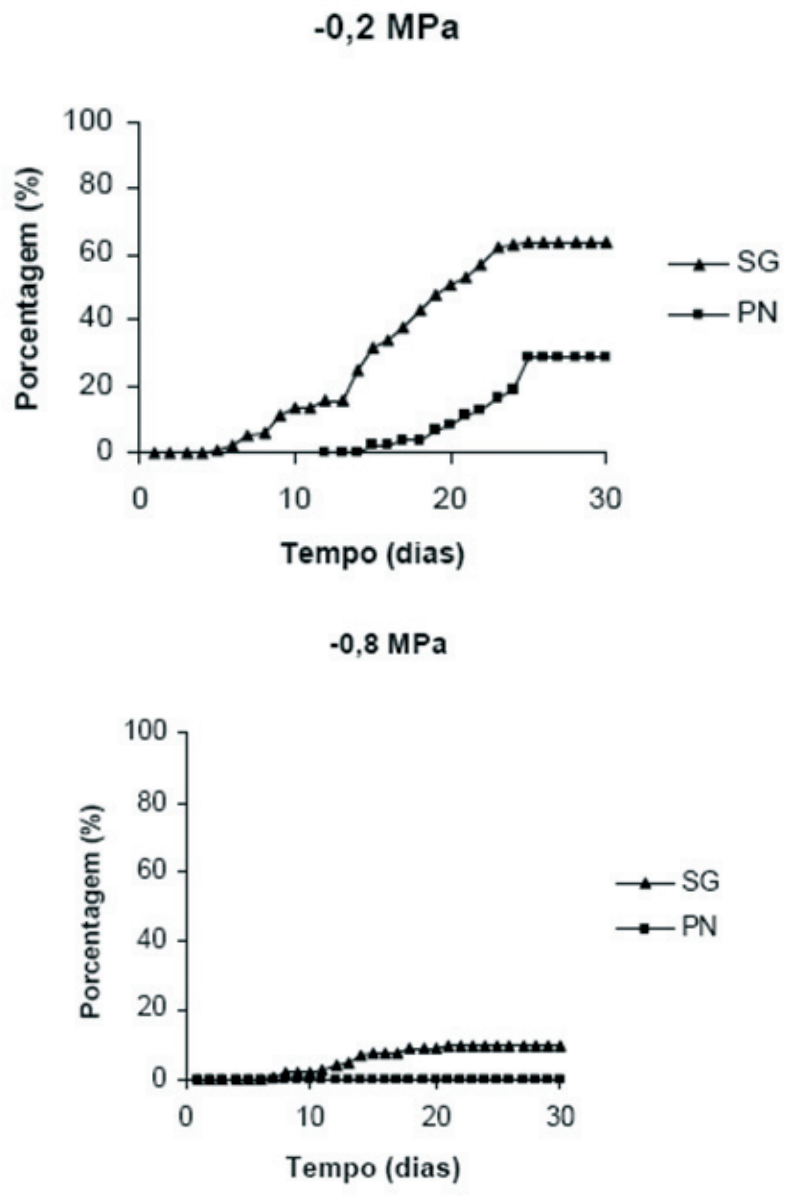

$-1,2 \mathrm{MPa}$

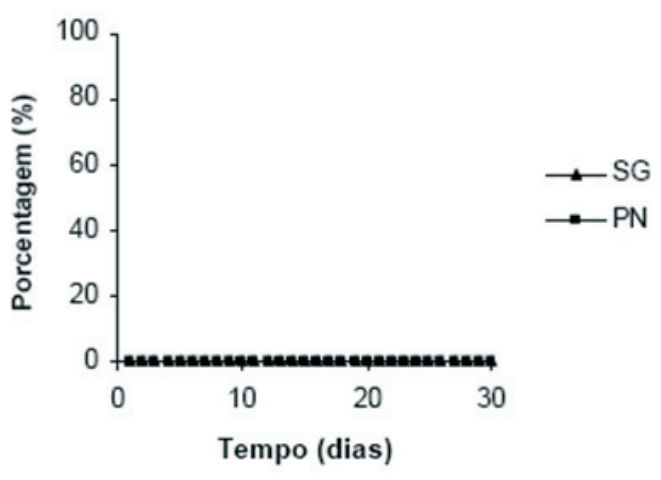

FIGURA 2. Porcentagens acumuladas de germinação (SG) e de formação de plântulas normais (PN) de cerejeira submetidas a diferentes potenciais hídricos. 
Para várias outras espécies também foram observadas reduções na germinação e na velocidade de germinação, em graus variados, como em Plantago ovata (Sousa, 2004), Pterogyne nitens (Nassif e Perez, 1997) e Adenanthera pavonina L. (Fanti e Perez, 1998), com a redução do potencial hídrico.

Mesmo ocorrendo formação de plântulas normais de cerejeira nos potenciais de $-0,2$ e $-0,4 \mathrm{MPa}$, esses valores foram muito baixos, entre 29 e $18 \%$ respectivamente. Pequenas restrições hídricas seriam suficientes para promover a distribuição da emergência no tempo, aumentando as chances de sobrevivência das plântulas a estresses hídricos não periódicos. Essa espécie é de ocorrência em matas altas e fechadas na Amazônia, onde predominam umidades relativas elevadas e grande quantidade de precipitações anuais, o que evidencia a afirmação de Borghetti e Ferreira (2004) que a distribuição geográfica das espécies depende, em grande parte, da capacidade de suas sementes de germinar sob as condições climáticas predominantes.

\section{CONCLUSÕES}

A germinação de sementes de cerejeira ocorre em temperaturas entre 20 e $40^{\circ} \mathrm{C}$, sendo que não há formação de plântulas normais a $40^{\circ} \mathrm{C}$. Para a realização do teste de germinação a temperatura mais adequada é $30^{\circ} \mathrm{C}$.

Potenciais hídricos no ambiente de germinação de -0,2MPa já reduzem a formação de plântulas normais, embora a germinabilidade não seja alterada nessas condições. Não ocorre germinação a -1,2 MPa e formação de plântulas normais a $-0,8 \mathrm{MPa}$.

\section{REFERÊNCIAS}

ALBRECHT, J.M.F.; ALBUQUERQUE, M.C.F.; SILVA; V.S.M. Influência da temperatura e do tipo de substrato na germinação de sementes de cerejeira. Revista Brasileira de Sementes, Brasília, v.8, n.1, p.49-55, 1986.

AÑEZ, L.M.M.; VUADEN, E.R.; OLIVEIRA, S.S.; ALBUQUERQUE, M.C.F.; COELHO, M.F.B. Temperaturas para germinação de sementes de mama cadela (Brosimum gaudichaudii Trec-Moraceae). Revista Agricultura Tropical, Cuiabá, v.6, n.1, p.167-176, 2002.

BEWLEY, J.D.; BLACK, M. Seeds: physiology of development and germination. 2 ed. New York: Plenum, 1994, 445p.

BORGES, E.E.L.; RENA, A.B. Germinação de sementes. In:
AGUIAR, I.B.; PINÃ- RODRIGUES, F.C.M.; FIGLIOLIA, M.B. (Coord.). Sementes florestais tropicais. Brasília: ABRATES, 1993. 350p.

BORGES, E.E.L.; VASCONCELOS, P.C.S.; CARVALHO, D.V.; BORGES, R.C.G. Estudos preliminares sobre o efeito do estresse hídrico na germinação de sementes de jacarandáda-bahia (Dalbergia nigra) e cedro-rosa (Cedrela fissilis). Revista Brasileira de Sementes, Brasília, v.13, n.2, p.115$118,1991$.

BORGHETTI, F.; FERREIRA, A.G. Interpretação de resultados de germinação. In: FERREIRA, A.G.; BORGHETTI, F. (ED). Germinação: do básico ao aplicado. Porto Alegre: Artmed, 2004.p.209-222.

BRADFORD, K.J. Water stress and the water relations of seed development: a critical review. Crop Science, Madison, v.34, p.1-11, 1994.

BRASIL. Ministério da Agricultura Reforma Agrária. Regras para análise de sementes. Brasília: SNDA/DNPV/ CLAV, 1992. 365p.

CARVALHO, N.M.; NAKAGAWA, J. Sementes: ciência, tecnologia e produção. 4. ed. Jaboticabal: FUNEP, 2000. 588 p.

CARVALHO, P.E.R. Espécies florestais brasileiras: recomendações silviculturais, potencialidades e uso da madeira. Embrapa - CNPF/ SPI. Colombo: 1994. 640p.

COPELAND, L.O.; MacDONALD, M.B. Principles of seed science and technology. 3 ed. New York: Chapman \& Hall, 1995. 409p.

DIGNART, S. Análise de sementes de jatobá do cerrado [Hymenaea stigonocarpa (Hayne) Mart.] e barbatimão [Stryphnodendron adstringens (Mart.) Cov.]. 1998, 58f. Dissertação (Mestrado em Agricultura Tropical) - Faculdade de Agronomia e Medicina Veterinária, Universidade Federal de Mato Grosso, Cuiabá-MT, 1998.

FANTI, S.C. Aspectos da germinação e efeitos do condicionamento osmótico em sementes de paineira (Chorisia speciosa St. Hil.- Bombacaceae). 2001, 145f. Tese (Doutorado em Ciências) - Centro de Ciências Biológicas e da Saúde, UFSCar, São Carlos-SP, 2001.

FANTI, S.C.; PEREZ, S.C.J.A. Efeitos do estresse hídrico, salino e térmico no processo germinativo de sementes de Adenanthera pavonina L. Revista Brasileira de Sementes, Brasília, v.20, n.1, p.167-177, 1998.

LABOURIAU, L.G. A germinação das sementes. Washington D.C.: Secretaria Geral da Organização dos Estados Americanos, Programa Regional de Desenvolvimento 
Científico e Tecnológico. 1983. 174p.

LARCHER, W. Ecofisiologia vegetal. Trad. De C.H.B.A. Prado. São Carlos: RIMA, 2000. 531p.

LORENZI, H. Árvores brasileiras: manual de identificação e cultivo de plantas arbóreas nativas do Brasil. 4 ed. Nova Odessa, SP: Editora Plantarum, 2002. v.1, 368p.

MIRANDA, P.R.M.; FERRAZ, I.D.K. Efeito da temperatura na germinação de sementes e morfologia da plântula de Maquira sclerophylla (Ducke). Revista Brasileira de Botânica, São Paulo, v.22, n.2 (suplemento), p.303-307, 1999.

MOORE, M.B.; KID, F.A. Seed source variation in induced moisture stress germination of ponderosa pines. Tree Planters Notes, v.33, p.12-14, 1982.

NASSIF, S.M.L.; PEREZ, S.C.J.G.A. Germinação de sementes de amendoim do campo (Pterogyne nitens): influência dos tratamentos para superar a dormência e profundidade de semeadura. Revista Brasileira de Sementes, Brasília v.19, n.2, p.172-179, 1997.
POPINIGIS, F. Fisiologia da semente. Brasília: Agiplan, 1985. 209p.

SANTOS, V.L.M.; CALIL, A.C.; RUIZ, H.A.; ALVARENGA, E.M.; SANTOS, C.M. Efeito do estresse salino e hídrico na germinação e vigor de sementes de soja. Revista Brasileira de Sementes, Brasília, v.14, n.2, p.189194, 1992.

SOUSA, M.P. Germinação de sementes de Plantago ovata: estresse hídrico e salino, teor de prolina e atividade das enzimas amilase e ascorbato peroxidase. 2004. 80f. Tese (Doutorado em Ciências Biológicas) - Instituto de Biociências de Botucatu, Universidade Estadual Paulista, Botucatu-SP, 2004.

SOUZA, G.M.; CARDOSO, V.J.M. Effects of different environmental stresses on seed germination. Seed Science and Technology, Zürich, v.28, p.621-630, 2000.

VILLELA, F.A.; DONI FILHO, L.; SEQUEIRA, E.L. Tabela de potencial osmótico em função da concentração de polietileno glicol 6000 e da temperatura. Pesquisa Agropecuária Brasileira, Brasília, v.27, p.1311-1317, 1991. 